\title{
DEVELOPING VEGETABLES CARD MEDIA AS A LEARNING MEDIA FOR ELEMENTARY SCHOOL STUDENTS
}

\author{
PENGEMBANGAN MEDIA KARTU SAYURAN \\ SEBAGAI MEDIA PEMBELAJARAN UNTUK SISWA SEKOLAH DASAR
}

\author{
Dina Fadhilah, Theresia Ninuk Sri Hartini, I Made Alit Gunawan, Ayu Triani \\ Jurusan Gizi, Poltekkes Kemenkes Yogyakarta
}

Article Info
Article history:
Received Feb $21^{\text {th }}, 2018$
Revised Mar $10^{\text {th }}, 2018$
Accepted Apr $16^{\text {th }}, 2018$

Keyword:

Media

Cards

Vegetables

Elementary

School

Student

\section{Kata Kunci :}

Media

Kartu

Sayuran

Anak Sekolah Dasar

\section{ABSTRACT/ABSTRAK}

Nutrition education efforts in schools have a great opportunity to successfully improve the knowledge of nutrition among the community because school students are expected to be a bridge for teachers with their parents, teachers as educators in the teaching and learning process have an influence on their students who are sometimes more comply than parents. Nutrition education should be given as early as possible, because children generally have a high desire to know and learn something further. The appropriate age of children to be given nutritional education is at 6-14 years, because this is the intellectual period in which children begin to learn. From the range, the most appropriate time in giving nutritional counseling is at the age of 11 years because at that age children are in the formal operational stage, which means able to think in abstract, build logical reasoning, and draw the conclusions of available information. The right media will increase the spirit of self-study according to the environment and enable students to learn by themselves according to their interests and abilities. Media must be created by not ruling out good and correct media requirements, so that information can be received in accordance with the wishes of the messenger. This research is a media development research. Starting by designing the format of the form and the content of the media. Furthermore the card was validated by 2 media experts; those were a lecturer in Health Polytechnic of Ministry of Health in Yogyakarta and a graphic designer. Then it was tested to 20 students of class $V$ of academic year 2016/2017 in SDN Nglahar 1, Yogyakarta. The data were collected using questionnaire and then analyzed. The results concluded that vegetables cards developed were feasible to use. Presentation of feasibility based on validation result from lecturer and graphic design was $80.32 \%$ (feasible) as well as response from elementary school student equaled to $80.74 \%$ (feasible).

\begin{abstract}
Upaya pendidikan gizi di sekolah berpeluang besar untuk berhasil meningkatkan pengetahuan tentang gizi di kalangan masyarakat karena siswa sekolah diharapkan dapat menjadi jembatan bagi guru dalam menjangkau orang tuanya, guru sebagai tenaga pendidik dalam proses belajar mengajar mempunyai pengaruh terhadap anak-anak didiknya yang kadang-kadang lebih dituruti daripada orang tua. Pendidikan gizi sebaiknya diberikan sedini mungkin, karena anak-anak umumnya mempunyai keinginan tinggi untuk mengetahui dan mempelajari sesuatu lebih jauh. Usia anak yang sesuai untuk diberikan pendidikan gizi adalah anak yang berada pada periode $6-14$ tahun, karena pada usia ini merupakan periode intelektual dimana anak mulai untuk belajar. Dari rentang tersebut yang paling tepat diberikan penyuluhan gizi adalah usia 11 tahun karena pada usia tersebut anak berada dalam tahapan operasional formal, yaitu mampu untuk berpikir secara abstrak, menalar secara logis menarik kesimpulan dari informasi yang tersedia. Media yang tepat akan menimbulkan semangat belajar sendiri sesuai dengan lingkungan dan memungkinkan siswa belajar sendiri sesuai dengan minat dan kemampuannya. Media harus dibuat dengan tidak mengesampingkan syarat media yang baik dan benar, agar informasi dapat diterima sesuai dengan keinginan penyampai pesan. Penelitian ini adalah penelitian pengembangan media. Diawali dengan merancang format bentuk dan isi media, Selanjutnya kartu divalidasi oleh 2 orang ahli media yaitu dosen Politeknik Kesehatan Kementerian Kesehatan Yogyakarta yang dan Desain grafis, lalu diujicobakan kepada 20 siswa kelas V Tahun ajaran 2016/2017 di SDN Nglahar 1,Yogyakarta. Metode pengumpulan data menggunakan metode angket dan dianalisis. Hasil penelitian menyimpulkan bahwa kartu sayuran yang dikembangkan layak untuk dipergunakan. Presentasi kelayakan berdasarkan hasil validasi dari dosen dan design grafis sebesar $80,32 \%$ (layak) begitupun juga respon dari siswa SD sebesar $80,74 \%$ (layak).
\end{abstract}

Copyright (C) Jurnal Teknologi Kesehatan (Journal of Health Technology). All rights reserved.

\section{Corresponding Author:}

Dina Fadhilah,

Jurusan Gizi,

Poltekkes Kemenkes Yogyakarta,

Jl. Tatabumi No.3 Banyuraden, Gamping, Sleman, Yogyakarta

Email: dina fadhilah@yahoo.com 


\section{PENDAHULUAN}

Media berasal dari bahasa latin medius, yang secara harfiah berarti "tengah", "perantara" atau "pengantar dapat diartikan sebagai perantara atau pengantar pesan dari pengirim ke penerima pesan. Media dapat berupa sesuatu bahan (software) dan/atau alat (hardware) ${ }^{1,2}$.

Media pembelajaran adalah segala sesuatu yang menyangkut software dan hardware yang dapat digunakan untuk menyampaikan isi materi ajar dari sumber belajar ke objek belajar (individu atau kelompok), yang dapat merangsang pikiran, perasaan, perhatian dan minat objek belajar sedemikian rupa sehingga proses belajar (di dalam/di luar kelas) menjadi lebih efektif. Media pembelajaran mencakup: a). Media sebagai alat komunikasi guna lebih mengefektifkan proses belajar mengajar; b). Fungsi media alam rangka mencapai tujuan pendidikan; c). Seluk beluk proses belajar; d). Hubungan antara metode mengajar dan media pendidikan; e). Nilai atau manfaat media pendidikan dalam pengajaran; f). Pemilihan dan penggunaan media pendidikan; g). Berbagai jenis alat dan teknik media pendidikan; h). Media pendidikan dalam setiap mata pelajaran; i). Usaha inovasi dalam media pendidikan ${ }^{3}$.

Penggunaan media secara kreatif akan memungkinkan audien untuk belajar lebih baik dan dapat meningkatkan performa mereka sesuai dengan tujuan yang ingin dicapai. Tujuan penggunaan media sebagai sumber belajar adalah untuk memudahkan anak didik memperoleh pengetahuan dan keterampilan, ketidakjelasan bahan yang disampaikan dapat dibantu dengan menghadirkan media sebagai perantara ${ }^{4}$.

Karakteristik media merupakan dasar pemilihan media sesuai dengan situasi belajar tertentu. Klasifikasi media, karakteristik media dan pemilihan media merupakan kesatuan yang tidak terpisahkan dalam penentuan strategi pembelajaran. Berikut beberapa karakteristik jenis media yang lazim digunakan: 1) Media Grafis atau Visual; 2) Media 3) Berbasis Audio Visual; 4) Media Proyeksi Diam.

Media grafis dalam bentuk gambar merupakan salah satu jenis media yang lazim dipakai dalam kegiatan belajar di Indonesia. Media grafis dalam bentuk gambar merupakan media yang termasuk sederhana, mudah dalam pembuatannya serta relative murah. Kelebihan media gambar adalah bersifat konkrit/realistis dalam menunjukan pokok masalah, dapat mengatasi batasan ruang dan waktu, dapat mengatasi keterbatasan pengamatan, dapat memperjelas suatu masalah di dalam bidang apa saja dan untuk tingkat usia berapa saja sehingga dapat mencegah atau memperbaiki kesalahpahaman.

Media kartu merupakan salah satu media visual yang tidak diproyeksikan. Media kartu berisi materi ajar berupa gambar, keterangan gambar, pertanyaan atau jawaban pertanyaan sesuai dengan materi yang akan disajikan juga mengandung unsur belajar sebagai unsur pokok dan permainan sebagai unsur hiburan. Penggunaan media ini diharapkan agar perhatian siswa terhadap materi pelajaran yang disampaikan oleh guru dapat meningkat, sehingga hasil belajar yang dicapai siswa lebih baik ${ }^{5}$.

Kegiatan pembelajaran dengan menggunakan media kartu bergambar sangat baik untuk membangkitkan semangat belajar siswa, melatih kepekaan siswa terhadap suatu objek dan merangsang daya imajinasi sehingga siswa mudah mengenali objek-objek yang ada disekitarnya. Strategi pembelajaran kartu memungkinkan siswa dapat aktif belajar secara berkelompok, berkompetisi secara sehat, dapat berkomunikasi 3 arah dan pembelajaran dapat terwujud dengan menyenangkan semua pihak. Hal tersebut tampak pada hasil observasi yang dilakukan peneliti mengenai proses pemanfaatan media permainan kartu hitung dengan sumber data guru dan siswa ${ }^{6,7}$.

Hasil studi pendahuluan pada 20 orang anak usia 9 - 12 tahun di Kecamatan Godean, Kabupaten Sleman menyatakan hanya mengkonsumsi sayuran $1-2$ porsi perharinya. Oleh karena itu, perlu adanya peningkatan pengetahuan gizi melalui kegiatan penyuluhan gizi khususnya tentang sayuran untuk anak sekolah dasar. Banyak alat dan cara yang dapat digunakan untuk meningkatkan pengetahuan, 
kewaspadaan dan perilaku makan anak. Media yang tepat akan menimbulkan semangat belajar sendiri sesuai dengan lingkungan dan memungkinkan siswa belajar sendiri sesuai dengan minat dan kemampuannya. Media harus dibuat dengan tidak mengesampingkan syarat media yang baik dan benar, agar informasi dapat diterima sesuai dengan keinginan penyampai pesan².

Berdasarkan uraian latar belakang tersebut, Peneliti tertarik melakukan penelitian pengembangan media tentang sayuran untuk siswa Sekolah Dasar".

\section{METODE PENELITIAN}

Metode penelitian ini merupakan metode penelitian dan pengembangan (Research and Development $(R \& D)$ ). Pembuatan media diawali dengan merancang format media yang terdiri dari bentuk, ukuran, materi, konten, dan warna media kartu yang bertema sayuran yang didalamnya mengandung unsur belajar sebagai unsur pokok, dan permainan sebagai unsur hiburan. Selanjutnya kartu divalidasi oleh 2 orang ahli yang berkompeten di bidang media yaitu desainer grafis dan dosen Poltekkes Kemenkes Yogyakarta yang berkompeten tentang materi yang ditampilkan dimedia kartu, lalu diujicobakan kepada 20 siswa kelas V Tahun ajaran 2016/2017 di SDN Nglahar 1,Yogyakarta. Penelitian dan pengumpulan data dilaksanakan pada Bulan Maret - April 2017 di SDN Godean 2.

Metode pengumpulan data dalam penelitian ini adalah dengan menggunakan metode angket meliputi angket telaah, angket validasi, dan angket respon siswa. Data yang diperoleh kemudian di analisis.

Teknik pengumpulan data menggunakan metode angket untuk mengumpulkan penilaian dosen dan desainer grafis terhadap media kartu tema sayuran, serta angket respon siswa. Data yang diperoleh selama penelitian dianalisis secara kualitatif dan deskriptif kuantitatif. Media dikatakan layak apabila semua aspek dalam angket mendapat persentase sebesar $\geq 61 \%$ dengan kriteria layak dan sangat layak $^{8,9}$.

\section{HASIL DAN PEMBAHASAN}

Penelitian ini merupakan penelitian pengembangan media yaitu mengembangan media kartu dengan tema sayuran, yang bertujuan untuk menciptakan media sebagai sumber belajar untuk memudahkan anak didik memperoleh pengetahuan dan keterampilan, serta memperjelas suatu masalah di dalam bidang apa saja dan untuk tingkat usia berapa saja sehingga dapat mencegah atau memperbaiki kesalahpahaman.

Media kartu berisi materi ajar berupa gambar, keterangan gambar, pertanyaan atau jawaban pertanyaan sesuai dengan materi yang akan disajikan juga mengandung unsur belajar sebagai unsur pokok dan permainan sebagai unsur hiburan. Penggunaan media ini diharapkan agar perhatian siswa terhadap materi pelajaran yang disampaikan oleh guru dapat meningkat, sehingga hasil belajar yang dicapai siswa lebih baik.

\subsection{Tema dan bentuk media}

Tema yang ambil adalah sayuran sedangkan bentuk medianya adalah kartu dengan tujuan siswa SD akan belajar sambil bermain kartu. Kartu yang dibuat berbentuk persegi panjang dengan ukuran $8 \times 10 \mathrm{~cm}$ dengan jumlah keseluruhan kartu sebanyak 25 lembar. Proses pembuatan Kartu Sayuran dimulai dari pencarian gambar dan konten yang sesuai tema yaitu sayuran. Gambar-gambar yang dipakai berasal dari internet dengan format jpg yaitu gambar sayuran dan tokoh dalam film kartu "Adit, Sopo, Jarwo". Sayuran yang dipilih antara lain: lobak, wortel, jamur tiram, jamur kuping, kangkung, daun papaya, daun singkong, sawi, bayam, caisin, seledri, kubis, brokoli, kembang 
kol, terong, melinjo, labu siam, mentimun, tomat, oyong/gambas, papaya muda, jagung muda, kacang panjang, taoge dan buncis. Sedangkan gambar tokoh kartun yang dipilih adalah: Adit, Jarwo, Pa Haji, Adel, Mia dan Mita. Setelah gambar-gambar disesuaikan dengan tema yang dipilih. Dilakukan proses desain kartu sayuran menggunakan program corel draw. Setelah proses desain selesai kemudian dilakukan proses editing untuk menyempurnakan kartu sayuran. Terakhir, setelah dilakukan proses editing maka dilakukan pencetakan kartu sayuran. Kriteria format tampilan, materi serta bahasa media disesuaikan dengan tema kartu yaitu sayuran dan usia responden.

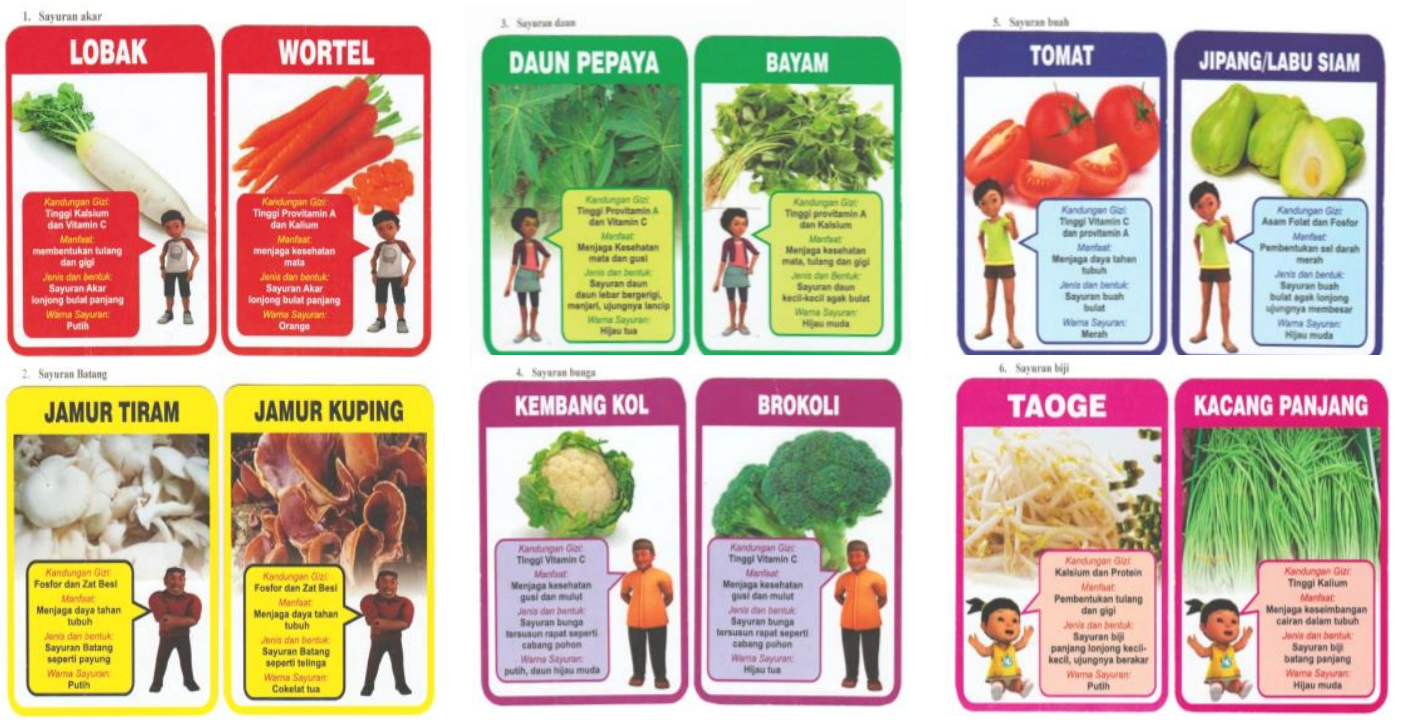

Gambar 1. Contoh Tampilan Media Kartu Sayuran

\subsection{Kelayakan Penilaian Media (Kartu Sayuran)}

Untuk menilai kelayakan suatu media pembelajaran dibutuhkan validator yang dianggap mampu/ahli dalam bidang media yang akan diciptakan. Ada dua validator yang digunakan dalam penilaian kelayakan medi kartu sayuran, pertama yaitu dosen Poltekkes Kemenkes Yogyakarta yang menguasai isi materi dan validator kedua adalah ahli media yang menguasai dalam hal tampilan media.

Tabel 1. Penilaian Tampilan Media "Kartu Sayuran" oleh Dosen

\begin{tabular}{clc}
\hline $\mathbf{N}$ & \multicolumn{1}{c}{ Aspek yang dinilai } & $\begin{array}{c}\text { Kelayakan } \\
\text { (\%) }\end{array}$ \\
\hline 1 & Penampilan sampul "kartu sayuran" & 75 \\
2 & Keterbacaan tulisan dengan jenis dan ukuran huruf yang & 80 \\
& sesuai & \\
3 & Gambar dan ilustrasi yang digunakan sesuai dengan & 80 \\
& materi & 80 \\
4 & Latar belakang sederhana & 80 \\
5 & Ukuran gambar & 85 \\
6 & Penyajian gambar menarik perhatian & 80 \\
7 & Ukuran kartu proporsional & 85 \\
8 & Ketebalan kartu & 85 \\
9 & Pemilihan warna sesuai & $\mathbf{8 1 , \mathbf { 1 1 }}$ \\
\hline
\end{tabular}

Keterangan nilai kelayakan : (Sumber : Ridwan, 2010)

$0 \%-60 \%=$ Kurang layak $\quad 61 \%-100 \%=$ Layak 
Tabel 2. Penilaian Tampilan Media "Kartu Sayuran" oleh Ahli Media

\begin{tabular}{clc}
\hline No & \multicolumn{1}{c}{ Aspek yang dinilai } & $\begin{array}{c}\text { Kelayakan } \\
(\%)\end{array}$ \\
\hline 1 & Penampilan sampul "kartu sayuran" & 75 \\
2 & Keterbacaan tulisan dengan jenis dan ukuran huruf yang & 85 \\
& sesuai & \\
3 & Gambar dan ilustrasi yang digunakan sesuai dengan & 85 \\
& materi & 70 \\
4 & Latar belakang sederhana & 85 \\
5 & Ukuran gambar & 80 \\
6 & Penyajian gambar menarik perhatian & 85 \\
7 & Ukuran kartu proporsional & 75 \\
8 & Ketebalan kartu & 80 \\
9 & Pemilihan warna sesuai & $\mathbf{8 0}$ \\
\hline
\end{tabular}

Keterangan nilai kelayakan : (Sumber : Ridwan, 2010)

$0 \%-60 \%=$ Kurang layak $\quad 61 \%-100 \%=$ Layak

Siswa sebagai responden uji coba penelitian pengembangan media kartu sayuran sangat antusias saat diberikan media kartu sayuran untuk dinilai. Responden memberikan respon positif dalam proses belajar mengajar di dalam kelas dengan metode belajar sambil bermain.

Tidak jauh berbeda dengan hasil analisis oleh validator, hasil analisis dari uji coba pada 20 orang siswa SDN Nglahar1 mengenai tampilan, materi dan bahasa media kartu sayuran adalah layak. Walaupun hasil analisis mengenai bahasa media kartu sayuran lebih sedikit dibandingkan dengan penilaian tampilan dan materi pada media kartu sayuran. Hasil penilaian kelayakan tampilan, materi dan bahasa media "Kartu Sayuran" oleh siswa SD dapat dilihat pada tabel 3, 6 , dan 9 berikut ini.

Tabel 3. Penilaian Tampilan Media "Kartu Sayuran" oleh Siswa SD

\begin{tabular}{|c|c|c|c|c|}
\hline \multirow[t]{2}{*}{ No } & \multirow[t]{2}{*}{ Aspek yang dinilai } & \multicolumn{2}{|c|}{$\begin{array}{l}\text { Jawaban } \\
\text { Siswa }\end{array}$} & \multirow{2}{*}{$\begin{array}{c}\text { Skor } \\
(\%)\end{array}$} \\
\hline & & Ya & Tidak & \\
\hline 1 & Penampilan sampul "kartu sayuran" & 17 & 3 & 85 \\
\hline 2 & $\begin{array}{l}\text { Keterbacaan tulisan dengan jenis dan ukuran } \\
\text { huruf yang sesuai }\end{array}$ & 17 & 3 & 85 \\
\hline 3 & $\begin{array}{l}\text { Gambar dan ilustrasi yang digunakan sesuai } \\
\text { dengan materi }\end{array}$ & 18 & 2 & 90 \\
\hline 4 & Latar belakang sederhana & 18 & 2 & 90 \\
\hline 5 & Ukuran gambar & 15 & 5 & 75 \\
\hline 6 & Penyajian gambar menarik perhatian & 16 & 4 & 80 \\
\hline 7 & Ukuran kartu proporsional & 15 & 5 & 75 \\
\hline 8 & Ketebalan kartu & 15 & 5 & 75 \\
\hline 9 & Pemilihan warna sesuai & 18 & 2 & 90 \\
\hline & Rata-rata & & & 82.78 \\
\hline
\end{tabular}

Keterangan nilai kelayakan : (Sumber : Ridwan, 2010)

$0 \%-60 \%=$ Kurang layak $\quad 61 \%-100 \%=$ Layak

Hasil analisis penilaian tampilan media "Kartu Sayuran" oleh kedua validator (dosen dan ahli media) dan uji coba pada siswa SD pada tabel 1, 2, dan 3 didapatkan hasil bahwa media "kartus sayuran" memiliki penilaian lebih dari $61 \%$, sehingga dapat disimpulkan bahwa tampilan media "Kartu Sayuran" layak digunakan. 
Tabel 4. Penilaian Materi Media "Kartu Sayuran" oleh Dosen

\begin{tabular}{clc}
\hline No & \multicolumn{1}{c}{ Aspek yang dinilai } & $\begin{array}{c}\text { Kelayakan } \\
(\%)\end{array}$ \\
\hline 1 & Tema sesuai dengan perkembangan kognitif siswa SD & 80 \\
2 & Penyajian konsep mudah dicerna & 80 \\
3 & Merangsang siswa untuk membaca & 80 \\
4 & Kelengkapan informasi & 85 \\
\hline \multicolumn{2}{c}{ Rata-rata }
\end{tabular}

Keterangan nilai kelayakan : (Sumber : Ridwan, 2010)

$0 \%-60 \%=$ Kurang layak $\quad 61 \%-100 \%=$ Layak

Tabel 5. Penilaian Materi Media "Kartu Sayuran" oleh Ahli Media

\begin{tabular}{clc}
\hline No & \multicolumn{1}{c}{ Aspek yang dinilai } & $\begin{array}{c}\text { Kelayakan } \\
(\%)\end{array}$ \\
\hline 1 & Tema sesuai dengan perkembangan kognitif siswa SD & 85 \\
2 & Penyajian konsep mudah dicerna & 85 \\
3 & Merangsang siswa untuk membaca & 90 \\
4 & Kelengkapan informasi & 85 \\
\hline \multicolumn{2}{c}{ Rata-rata } & $\mathbf{8 6 , 2 5}$ \\
\hline
\end{tabular}

Keterangan nilai kelayakan : (Sumber : Ridwan, 2010)

$0 \%-60 \%=$ Kurang layak $\quad 61 \%-100 \%=$ Layak

Tabel 6. Penilaian Materi Media "Kartu Sayuran" oleh Siswa SD

\begin{tabular}{|c|c|c|c|c|}
\hline \multirow[t]{2}{*}{ No } & \multirow[t]{2}{*}{ Aspek yang dinilai } & \multicolumn{2}{|c|}{$\begin{array}{l}\text { Jawaban } \\
\text { siswa }\end{array}$} & \multirow{2}{*}{$\begin{array}{l}\text { Skol } \\
(\%)\end{array}$} \\
\hline & & $\mathrm{Ya}$ & Tidak & \\
\hline 1 & $\begin{array}{l}\text { Tema sesuai dengan perkembangan kognitif } \\
\text { siswa SD }\end{array}$ & 15 & 5 & 75 \\
\hline 2 & Penyajian konsep mudah dicerna & 16 & 4 & 80 \\
\hline 3 & Merangsang siswa untuk membaca & 18 & 2 & 90 \\
\hline 4 & Kelengkapan informasi & 17 & 3 & 85 \\
\hline
\end{tabular}

Keterangan nilai kelayakan : (Sumber : Ridwan, 2010)

$0 \%-60 \%=$ Kurang layak $\quad 61 \%-100 \%=$ Layak

Berdasarkan hasil analisis penilaian materi media "Kartu Sayuran" oleh kedua validator (dosen dan ahli media) dan uji coba pada siswa SD pada tabel 4, 5 dan 6 didapatkan hasil bahwa media "kartus sayuran" memiliki penilaian lebih dari $61 \%$, sehingga dapat disimpulkan bahwa materi media "Kartu Sayuran" layak digunakan.

Tabel 7. Penilaian Penyajian Bahasa Media "Kartu Sayuran" oleh oleh Dosen

\begin{tabular}{|c|c|c|}
\hline No & Aspek yang dinilai & $\begin{array}{l}\text { Kelayakan } \\
(\%)\end{array}$ \\
\hline 1 & $\begin{array}{l}\text { Bahasa sesuai dengan perkembangan peserta didik } \\
\text { dengan menggunakan bahasa sederhana dan lazim } \\
\text { dipergunakan, singkat dan jelas }\end{array}$ & 80 \\
\hline 2 & $\begin{array}{l}\text { Menggunakan bahasa dengan struktur kalimat yang } \\
\text { tepat }\end{array}$ & 85 \\
\hline \multirow[t]{2}{*}{3} & $\begin{array}{l}\text { Istilah dan kosakata yang digunakan tepat dengan } \\
\text { konsep "sayuran" }\end{array}$ & 80 \\
\hline & Rata-rata & 81,66 \\
\hline
\end{tabular}

Keterangan nilai kelayakan : (Sumber : Ridwan, 2010)

$0 \%-60 \%=$ Kurang layak $\quad 61 \%-100 \%=$ Layak 
Tabel 8. Penilaian Penyajian Bahasa Media "Kartu Sayuran" oleh Ahli Media

\begin{tabular}{|c|c|c|c|c|}
\hline No & \multicolumn{2}{|l|}{ Aspek yang dinilai } & \multicolumn{2}{|c|}{$\begin{array}{l}\text { Kelayakan } \\
(\%)\end{array}$} \\
\hline 1 & $\begin{array}{l}\text { Bahasa sesuai dengan perkembangan peserta didik } \\
\text { dengan menggunakan bahasa sederhana dan lazim } \\
\text { dipergunakan, singkat dan jelas }\end{array}$ & & \multicolumn{2}{|c|}{70} \\
\hline 2 & $\begin{array}{l}\text { Menggunakan bahasa dengan struktur kalimat yang } \\
\text { tepat }\end{array}$ & & \multicolumn{2}{|c|}{70} \\
\hline 3 & $\begin{array}{l}\text { Istilah dan kosakata yang digunakan tepat dengan } \\
\text { konsep "sayuran" }\end{array}$ & & \multicolumn{2}{|c|}{75} \\
\hline & \multicolumn{2}{|l|}{ Rata-rata } & \multicolumn{2}{|c|}{71,67} \\
\hline \multicolumn{5}{|c|}{$\begin{array}{l}\text { Keterangan nilai kelayakan : (Sumber : Ridwan, 2010) } \\
0 \%-60 \%=\text { Kurang layak } \\
61 \%-100 \%=\text { Layak }\end{array}$} \\
\hline \multirow[t]{2}{*}{ No } & \multirow[t]{2}{*}{ Aspek yang dinilai } & \multicolumn{2}{|c|}{$\begin{array}{l}\text { Jawaban } \\
\text { siswa }\end{array}$} & \multirow{2}{*}{$\begin{array}{l}\text { Skor } \\
(\%)\end{array}$} \\
\hline & & $\mathrm{Ya}$ & Tidak & \\
\hline 1 & $\begin{array}{l}\text { Bahasa sesuai dengan perkembangan peserta } \\
\text { didik dengan menggunakan bahasa sederhana } \\
\text { dan lazim dipergunakan, singkat dan jelas }\end{array}$ & 15 & 5 & 75 \\
\hline 2 & $\begin{array}{l}\text { Menggunakan bahasa dengan struktur kalimat } \\
\text { yang tepat }\end{array}$ & 15 & 5 & 75 \\
\hline 3 & $\begin{array}{l}\text { Istilah dan kosakata yang digunakan tepat } \\
\text { dengan konsep "sayuran" }\end{array}$ & 16 & 4 & 80 \\
\hline
\end{tabular}

Rata-rata

Keterangan nilai kelayakan : (Sumber : Ridwan, 2010)

$0 \%-60 \%=$ Kurang layak $\quad 61 \%-100 \%=$ Layak

Berdasarkan hasil analisis penilaian penyajian bahasa media "Kartu Sayuran" oleh kedua validator (dosen dan ahli media) dan uji coba pada siswa SD pada tabel 7, 8, dan 9 didapatkan hasil bahwa media "kartus sayuran" memiliki penilaian lebih dari $61 \%$, sehingga dapat disimpulkan bahwa materi media "Kartu Sayuran" layak digunakan sebagai media belajar khususnya bagi siswa sekolah dasar.

Untuk validator kedua yang merupakan ahli media sebuah perusahan percetakan swasta menyimpulkan bahwa tampilan media kartu sayuran sudah baik, untuk materi media kartu sayuran sangat menarik karena temanya adalah sayuran. sedangkan untuk penilaian bahasa media kartu sayuran, hasil analisis menyatakan bahwa bahasa yang dipergunakan pada media kartu sayuran terlalu berat, hal ini wajar karena validator termasuk masyarakat awam yang tidak mengetahui istilah-istilah kesehatan khususnya bidang gizi. Tetapi kesimpulan akhir dari hasil analisis kedua validator adalah media kartu sayuran layak dipergunakan sebagai media belajar mengajar dengan metode balajar sambil bermain.

Media kartu sayuran dinyatakan efektif disebabkan juga karena penyematan tokoh yang familiar oleh responden. Pada kartu sayuran, tokoh yang disematkan adalah tokoh dalam film kartun "Adit, Sopo dan Jarwo" yaitu, Adit, Jarwo, Pa Haji, Adel, Mia dan Mita. Tokoh-tokoh tersebut dipilih karena berasal dari Indonesia, dikenal luas oleh masyarakat khususnya anak-anak dan dipilih yang postur tubuh ideal untuk memberikan pesan pada sampel bahwa salah satu criteria dari tubuh yang sehat tercermin dari postur tubuh yang ideal.

Penggunaan media pembelajaran bermanfaat untuk meningkatkan minat sasaran dalam menyerap informasi, membantu mengatasi banyak hambatan dalam pemahaman suatu materi, merangsang sasaran untuk meneruskan 
pesan-pesan yang diterima kepada orang lain, mempermudah penyampaian materi atau informasi oleh narasumber dan mempermudah penerimaan materi atau informasi oleh sasaran ${ }^{10,11}$.

Keefektifan belajar dengan metode belajar sambil bermain atau praktek langsung dapat meningkatkan penyerapan informasi yang diberikan. Hasil penelitian ini didukung oleh teori Dale $(1946)^{12}$ yang berpendapat bahwa yang disebut sumber belajar adalah pengalaman. la juga mengklasifikasikan pengalaman yang dapat dipakai sebagai sumber belajar menurut jenjang tertentu yang berbentuk cone of experience (kerucut pengalaman) dengan susunan paling atas adalah membaca $(10 \%)$, mendengar $(20 \%)$, melihat gambar atau menonton video (30\%), menghadiri seminar atau melihat demonstrasi $(50 \%)$, mengikuti workshop (70\%), dan simulasi atau praktek kerja lapangan (90\%).

Hasil penelitian ini selaras dengan hasil penelitia yang menyatakan bahwa pengetahuan siswa lebih meningkat dalam kegiatan promosi kesehatan dengan menggunakan media Kartu Bergambar. Sasaran promosi kesehatan di sekolah adalah guru, karena guru merupakan pengganti orang tua pada waktu di sekolah. Sekolah merupakan tempat untuk memberikan perilaku kesehatan kepada anak. Sekolah dan lingkungan sekolah yang sehat sangat tepat untuk berperilaku sehat bagi anak.

\section{KESIMPULAN}

Berdasarkan hasil penilaian kelayakan media kartu sayuran oleh validator (dosen dan ahli media) dan siswa SD sebagai pengguna media diperoleh hasil lebih dari $61 \%$ penilaian terhadap tampilan, materi, dan penyajian bahasa, sehingga dapat dinyatakan layak digunakan sebagai media belajar mengajar dengan metode balajar sambil bermain.

\section{DAFTAR PUSTAKA}

[1] Sadiman, A. 1999. Pengaruh televisi pada perubahan perilaku. Jurnal Teknologi Pendidikan.7 (IV).

[2] Sadiman, A. 2009. Media Pendidikan: Pengertian, Pengembangan dan Pemanfaatannya, edisi 1. Jakarta: PT. Raja Grafindo Persada.

[3] Mubarak. 2007. Promosi Kesehatan: Sebuah Pengantar Proses Belajar Mengajar dalam Pendidikan. Yogyakarta: Graha IImu.

[4] Arikunto, S. 2010. Prosedur Penelitian: Suatu Pendekatan Praktik. Jakarta: Rineka Cipta.

[5] Prawinda, D. 2012. Pengaruh Media Komik Gizi sebagai Pembelajaran Gizi terhadap Pengetahuan Gizi Siswa di SDN Tegal Panggung. Karya Tulis IImiah. Prodi D-III Jurusan Gizi Poltekkes Kemenkes Yogyakarta.

[6] Fatimah, A S. 2017. Efektifitas Penyuluhan Gizi Menggunakan PGS Card Dibandingkan Leaflet terhadap Peningkatan Pengetahuan Pedoman Gizi Seimbang pada Siswa Sekolah Dasar. Skripsi. Prodi D-IV Jurusan Gizi Poltekkes Kemenkes Yogyakarta.

[7] Sativa, D Y. 2012. Penggunaan Media Kartu untuk Meningkatkan Hasil Belajar Geografi Siswa Kelas XI IPS 1 SMA Kolombo Sleman Yogyakarta. Yogyakarta: Skripsi. Jurusan Pendidikan Geografi Fakultas IImu Sosial Universitas Negeri Yogyakarta.

[8] Purwanto, D. 2013. Pengembangan Media Komik IPA Terpadu Tema Pencemaran Air Sebagai Media Pembelajaran Untuk Siswa Smp Kelas VII. Jurnal Pendidikan Sains. 1 (1): $71-76$.

[9] Riduwan. 2010. Skala Pengukuran Variabel Variabel Penelitian. Bandung: Alfabeta

[10] Notoatmodjo, S. 2007. Promosi Kesehatan dan Ilmu Perilaku. Jakarta: Rineka Cipta.

[11] Notoatmodjo, S. 2010. Metodologi Penelitian Kesehaatan. Jakarta: Rineka Cipta.

[12] Dale, E. 1946. Audio-Visual Methods in Teaching. New York: Dryden Press. 